\title{
Diamond-forming Fluids and Kimberlites: The Trace Element Perspective.
}

\author{
Y. Weiss ${ }^{1}$, W. L. Griffin ${ }^{2}$, J. W. Harris ${ }^{3}$, O. Navon ${ }^{1}$ \\ ${ }^{1}$ Institute of Earth Sciences, The Hebrew University of Jerusalem, Israel \\ ${ }^{2}$ ARC National Key Centre for Geochemical Evolution and Metallogeny of Continents (GEMOC), \\ Macquarie University, NSW, Australia \\ ${ }^{3}$ Department of Geographical and Earth Sciences, University of Glasgow, Glasgow, Scotland
}

Major element studies of fluid inclusions in fibrous and cloudy diamonds reveal that most inclusions trapped high density fluids (HDFs) with a wide range of composition. The compositions fall along two arrays between three end-members: carbonatitic to hydroussilicic and carbonatitic to hydrous-saline. Recent studies of diamonds from Siberia and Kankan (Navon et al., 2008; Weiss et al., 2008) further subdivided the carbonatitic HDFs into: high-Mg and low-Mg groups.

Following the early neutron-activation work of Fesq et al. (1975) and Bibby (1979), Schrauder et al. (1996) measured the concentrations of 31 elements in fibrous diamonds from Jwaneng, Botswana. Akagi and Masuda (1988) burned Zairian fibrous diamonds and used isotope dilution mass-spectrometry to determine their $\mathrm{Sr}$ isotopic composition and $\mathrm{REE}, \mathrm{Sr}, \mathrm{Rb}, \mathrm{K}$ and Ba concentrations.

LA-ICP-MS now allows less destructive, in-situ analysis of the trace element content of diamonds. Tomlinson et al. (2005) reported trace element ratios of diamonds from Congo. Rege et al. (2005) introduced the external cellulose standard and used ${ }^{13} \mathrm{C}$ as internal standard to measure the trace element concentrations in diamonds. Comparison to earlier INAA and PIXE measurements of 23 elements in two samples yielded good correlations. Weiss et al. (in press) further tested the method and obtained good correlations between major elements/Fe concentration ratios for 28 microinclusion-bearing diamonds (Figure 1).

The agreement between four analytical methods, the small number of molecular interferences and the fact that the ablation pit is only $\sim 100 \mu \mathrm{m}$ across and $50-100$ $\mu \mathrm{m}$ deep make the cellulose-calibration LA-ICP-MS the most suitable technique for the determination of trace elements concentrations in diamonds. Calibrating the LA-ICP-MS data against the $\mathrm{K}_{2} \mathrm{O}$ of the HDFs measured by EPMA we calculate the trace element concentrations of the HDF itself.

The addition of water and carbonate concentrations estimated from FTIR, produces a comprehensive quantitative database of the HDF chemistry.

\section{Samples}

Twenty seven diamonds were chosen for this study: three diamonds from Kankan and six from Udachnaya carry high-Mg carbonatitic HDF. Three other Kankan

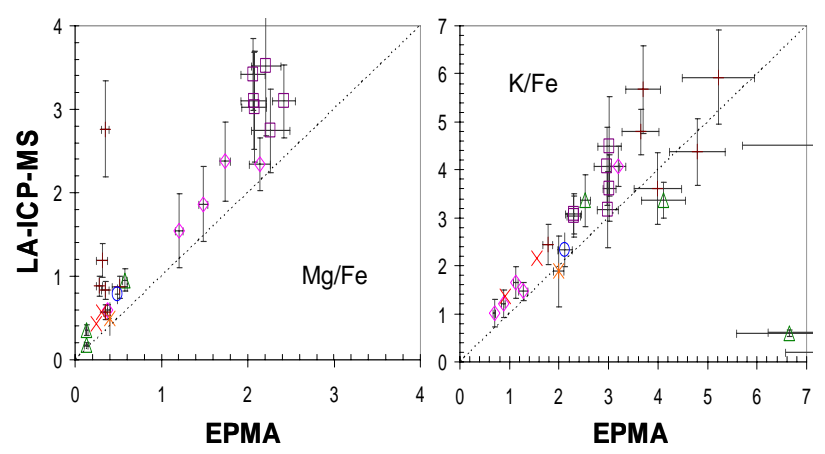

Figure 1: Comparison of $\mathrm{K} / \mathrm{Fe}$ and $\mathrm{Mg} / \mathrm{Fe}$ as measured by LA-ICP-MS and EPMA. The dotted lines mark the 1:1 slope, for the diamonds that deviate from this line and for original data see Weiss et al. (in press).

diamonds and single samples from Diavik, DeBeers Pool and Koingnaas carry low-Mg carbo-silicic HDFs. Five diamonds from Diavik, six from DeBeers Pool and a one from Koingnaas, carry saline fluids.

\section{Results}

The trapped HDFs in all diamonds are highly enriched with incompatible elements even in comparison to kimberlitic melts. $\mathrm{Ba}, \mathrm{Th}, \mathrm{U}$ and the light REE typically reach levels of a few thousand times the primitive mantle values (Figures 2-4). Note that in Figures. 2-4, the trace elements concentrations are of the volatile free composition of the HDF. Adding volatiles will shifts the whole pattern down, but by less than a factor of two.

Primitive-mantle normalized concentrations of high$\mathrm{Mg}$ carbonatitic HDFs from Udachnaya and Kankan reveal patterns that are distinct in their incompatible elements and merge for the more compatible ones (Figure 2). HDFs of the first have elevated $\mathrm{Ba}, \mathrm{U}, \mathrm{Th}$ and LREE, depleted $\mathrm{Nb}$ and $\mathrm{Ta}$ and highly depleted alkalis (we designated these "Table"). Those of the second have smoother pattern with somewhat low K, $\mathrm{Rb}$ and $\mathrm{Cs}$ (we designate this flatter pattern "Bench"). The average $\mathrm{La} / \mathrm{Dy}$ ratio of high-Mg carbonatitic HDFs with "Table" patterns is 225 while in the "Bench" ones, its value is only reaches 113 . Both patterns show negative anomalies of Sr, Hf, $\mathrm{Zr}$, Ti and Y. 


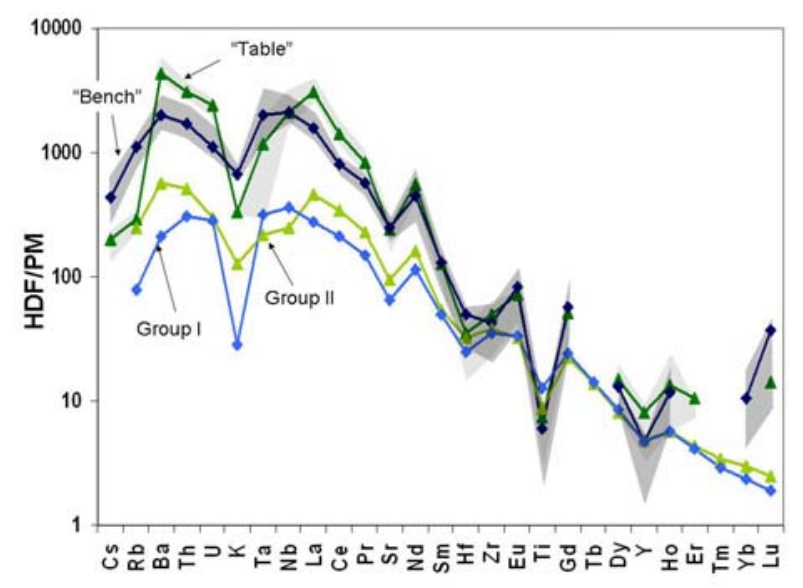

Figure 2: Trace elements of high-Mg carbonatitic HDFs in diamonds and kimberlites (normalized to primitive mantle composition). Light shaded area - the range for Kankan HDFs with "Table" pattern and their average (dark green triangles). Dark shaded area and dark blue diamonds "Bench" patterns in Udachnaya HDFs (the darkest grey is due to overlaps). Also shown are average Group I (light blue diamonds) and Group II (light green triangles) kimberlites (Becker and le Roex, 2005).

The low-Mg carbonatitic to silicic HDFs reveal similar distinction between "Tables" and "Benches" (Figure 3). Carbo-silicic HDFs with "Table" patterns from Kankan, DeBeers Pool and Diavik are strongly depleted in $\mathrm{Nb}$, Ta, Ti and usually also Sr. Their alkalis and HREE are higher than in the high-Mg carbonatitic HDFs, leading to shallower REE patterns. Their La/Dy ratio ranges from 20 to 200 and the ratio increases with increasing silica content.

In this study we did not find low-Mg carbonatitic HDFs showing the "Bench" patterns, but carbonatitic diamonds with low-Mg content from Jwaneng, Botswana (Schrauder et al., 1996) do show "Bench" characteristics with elevated alkalis and only small depletion of Ta. "Bench" patterns in silicic HDFs in diamonds from Koingnaas and Botswana are much smoother, with $\mathrm{Nb}$ and $\mathrm{Ta}$ having similar levels to $\mathrm{Ba}$, Th, $U$ and the LREE. The alkalis are elevated as well, sometimes even higher than the other most incompatible elements.

Figure 4 indicates that "Table" and "Bench" patterns are found in the saline fluids as well. HDFs from Diavik exhibit "Table" patterns with extreme enrichment of the incompatible elements (more than 10 $\mathrm{wt} \% \mathrm{Ba}$ are also indicated by EPMA measurements). A sample from Koingnaas has a very similar "Table" pattern but is lower in most incompatible elements. $\mathrm{Ba}$, Th and the LREE are high relative to $\mathrm{K}, \mathrm{Rb}, \mathrm{Cs}$, $\mathrm{Ta}, \mathrm{Nb}$ and $\mathrm{Sr}$ in those diamonds. In the compatible elements, $\mathrm{Ti}, \mathrm{Zr}$ and $\mathrm{Hf}$ are very low relative to the corresponding HREE. Uranium is not as enriched as Th, perhaps reflecting the low $\mathrm{Zr}$ content. A smoother "Bench" pattern is exhibited by diamonds from DeBeers Pool. Nb, Ta, Zr and Hf are only slightly below the respective REEs, $\mathrm{U}$ is elevated to the degree that the $(\mathrm{Th} / \mathrm{U})_{\mathrm{PM}}<1$, and $\mathrm{Sr}$ is higher than $\mathrm{Pr}$ and $\mathrm{Nd}$.

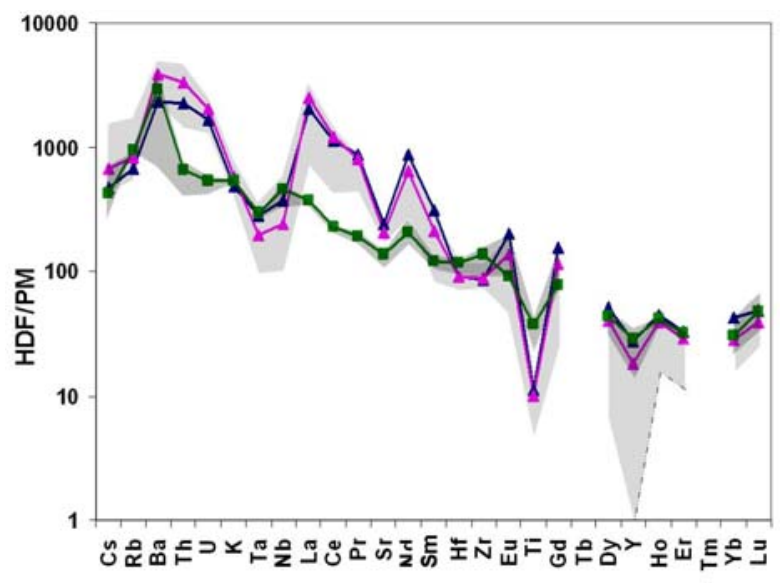

Figure 3: Trace elements in low-Mg carbo-silicic HDFs. Light shading: "Table" patterns. Blue and pink triangles: averages for more carbonatitic and more silicic HDFs respectively. Dark shading and green squares: "Bench" patterns and their average. The dotted line marks that in some diamonds, Ho falls below detection limit.

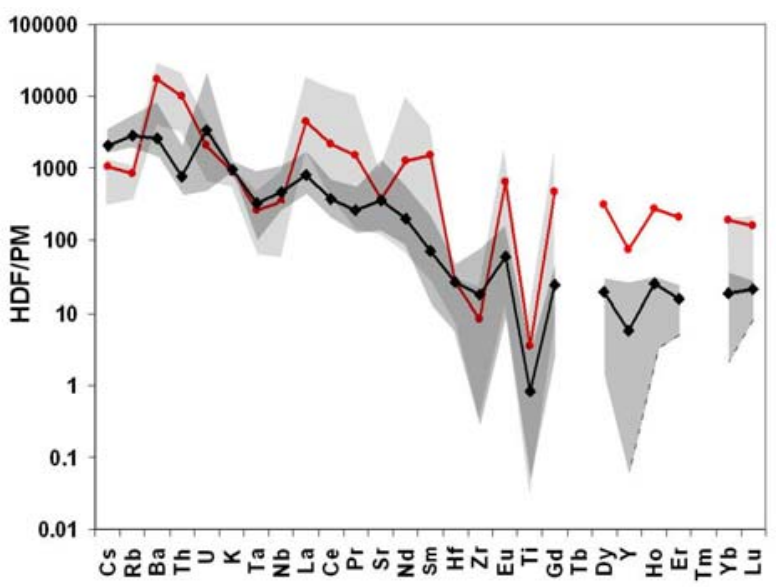

Figure 4: Trace elements in saline HDFs. Light shading and red circles - "Table" patterns and their average, dark shading and black diamonds - "Bench" patterns and average. Dotted lines as in Figure 2 for $\mathrm{Ho}$ and $\mathrm{Yb}$.

\section{Discussion}

The persistence of the two trace element patterns in fluids of such diverse major element compositions is fascinating. It indicates that the two patterns are not the result of differing fractionation paths from a common source and suggest that they originate from two different sources (or from interaction between fluids originating from different sources).

The present database is still limited, but "Table" patterns were found in the coat of a Kankan diamond that carries eclogitic inclusions in its core and in a Diavik diamond with peridotitic micro-mineral inclusions in its coat. Thus, the two patterns are probably not related to the peridotitic or eclogitic rocks that host the diamonds. The similarity in compatible elements that breaks in the incompatible ones suggest that the difference lies in the nature of the enriched sources that contribute to the very high abundance of most incompatible elements. 


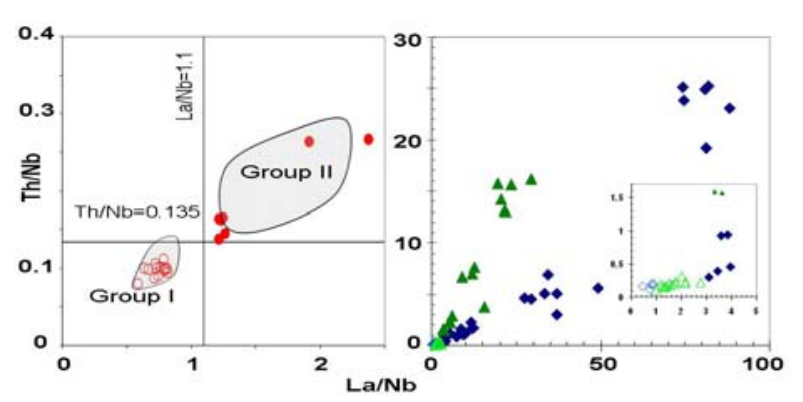

Figure 5: $\mathrm{Th} / \mathrm{Nb}$ vs. $\mathrm{La} / \mathrm{Nb}$ in the HDFs. (a) High-Mg carbonatitic HDFs with "Bench" patterns (open cricles) fall in the field of Group I kimberlites (shaded area). HDFs with "Table" patterns (solid circles) fall in the Group II field. (b) Carbonatitic-silicic HDFs with "Bench" (open diamonds) and "Table" (solid diamonds) patterns fall along a Th/La 0.25 line, Saline HDFs with Bench (open triangles) and Table (solid triangles) form a steeper array with $\mathrm{Th} / \mathrm{La} \sim 0.65$.

Figure 5a presents the similarity between the high-Mg carbonatitic HDFs and kimberlites. The "Tables" fall with Group II kimberlites, while the "Benches" fall in the field of Group I kimberlite. Figure 2 shows that the resemblance between the two patterns of the high-Mg carbonatitic HDFs and the corresponding kimberlite groups is maintained by most elements $(\mathrm{K}$ and $\mathrm{Rb}$ are exceptions with lower levels in diamonds with "Table" pattern and in Group I kimberlites). The concentration of the highly incompatible elements in the HDFs are 5 times higher than in kimberlites, but all patterns share the same negative anomalies and have similar concentrations of the moderately incompatible elements. The high enrichment of the fluids in many incompatible elements and the steeper REE patterns of the HDFs relative to kimberlites requires very low $\mathrm{HDF} /$ rock ratio during their formation (a lower degree of melting, or higher degree of crystallization). This agrees with their major element composition that is similar to that of near-solidus melts or supercritical fluids of peridotites and eclogites.

The variation in $\mathrm{Th} / \mathrm{Nb}$ and $\mathrm{La} / \mathrm{Nb}$ ratios in carbosilicic and carbo-saline HDFs show marked differences between the two groups. In HDFs with "Bench" patterns (open symbols) the ratios do not vary by much (open symbols in Figure 5b). In those with "Table" patterns the $\mathrm{Th} / \mathrm{Nb}$ ratios grow from $\sim 0.2$ in the high$\mathrm{Mg}$ to 1 in the low-Mg carbonatities and up to 25 in the silicic and 15 in the saline HDFs. The $\mathrm{La} / \mathrm{Nb}$ ratio varies accordingly from 1.5 to 4 and to 70 and 25 .

The huge variation of $\mathrm{Th} / \mathrm{Nb}$ and $\mathrm{La} / \mathrm{Nb}$ in the "Table" patterns can be achieved either by rutile addition (e.g., by dissolution during early melting) or removal (during fractionation). Similar arguments, based on major and trace elements may be made for the involvement of other phases, such as zircon, apatite mica and carbonates. Rocks rich in the above phases are known from xenoliths in kimberlites (e.g., the MARID and PIC rocks or glimmerites, Gregoire et al., 2002).

As the formation of such rocks involves crystallization from kimberlitic or other enriched melts, we enter a "chicken and egg" situation, which may describe true cycling of many incompatible elements between melts or fluids and accessory solid phases that crystallize last and melt/dissolve first upon heating or decompression of mantle rocks.

\section{Conclusions}

Major elements defined the nature of the HDFs and their 3-4 end member compositions. Trace element added the "Table" and "Bench" patterns that indicate the involvement of more than a single source for the incompatible elements of the HDFs. The "Table" patterns resemble Group II kimberlites and probably represent "re-cycling" of lithospheric material. The "Benches" resemble Group I kimberlites.

\section{References}

Akagi T. and Masuda A. (1988) Isotopic and elemental evidence for a relationship between kimberlite and Zaire cubic diamonds. Nature, 336, 665-667.

Becker, M., and le Roex A. P., 2006. Geochemistry of South African On- and Offcraton, Group I and Group II Kimberlites: Petrogenesis and Source Region Evolution. Journal of Petrology, 47, 673703.

Bibby, D.M., 1979. Zonal distribution of inclusions in diamond. Geochimica et Cosmochimica Acta, 43, 415-423.

Fesq, H.W., Bibby, D.M., Erasmus, C.S., Kable, E.J.D. and Sellschop, J.P.F., 1975. A comparative trace element study of diamonds from Premier, Finch and Jagersfontein mines, South Africa. Physics and Chemistry of the Earth, 9, 817-836.

Gregoire, M., Bell, D.R., Le Roex, A.P., 2002, Trace element geochemistry of phlogopite-rich mafic mantle xenoliths: their classification and their relationship to phlogopite-bearing peridotites and kimberlites revisited Contributions to Mineralogy and Petrology, 142, 603-625.

Navon, O., Klein-BenDavid O., Logvinova A. M., Sobolev N. V., Schrauder M., Kaminsky F. V., Spetius Z. V., 2008. Yakutian Diamond-forming fluids and the evolution of carbonatitic high-density fluids. 9th IKC, Extended Abstracts.

Rege, S., Jackson, S., Griffin, W.L., Davies, M.R., Pearson, N.J. and O'Reilly, S.Y., 2005. Quantitative trace-element analysis of diamond by laser ablation inductively coupled plasma mass spectrometry. Journal of Analytical Atomic Spectrometry, 20, 601-611.

Schrauder M., Koeberl C., and Navon O. (1996) Trace element analyses of fluid-bearing diamonds from Jwaneng, Botswana. Geochimica et Cosmochimica Acta, 60, 4711-4724.

Tomlinson, E., De Schrijver, I., De Corte, K., et al.., 2005. Trace element compositions of submicroscopic inclusions in coated diamond: A tool for understanding diamond petrogenesis. Geochemica et Cosmochemica Acta, 69, 4719-4732.

Weiss Y., Griffin W. L., Elhlou S., and Navon O. (in press) Comparison between LA-ICP-MS and EPMA analysis of trace elements in diamonds. Chemical Geology.

Weiss, Y., Kessel, R., Griffin, W. L., Kiflawi, I., Bell, D. R, Harris J. W., Navon, O., 2008. Diamond forming fluids from Kankan, Guinea: major and trace element study. 9th IKC, Extended Abstracts. 